\title{
RESISTÊNCIAS DO DIREITO PROCESSUAL PÚBLICO - ÀS PROMESSAS DO NOVO CÓDIGO DE PROCESSO CIVIL
}

Bruno Carlos Pastore ${ }^{1}$

PASTORE, B. C. Resistências do Direito Processual Público - às promessas do Novo Código de Processo Civil. Rev. Ciênc. Juríd. Soc. UNIPAR. Umuarama. v. 19, n. 1, p. 25-37, jan./jun. 2016.

RESUMO: A exposição de motivos do novo CPC, reconhecendo que justiça retardada é justiça denegada, exalta os princípios da razoável duração dos processos e da efetividade, para que pautem toda interpretação e aplicação do direito ao caso concreto. Não obstante, a ascensão e fortalecimento do Judiciário, dotado de autonomia e independência como nunca antes no Brasil, a autorrestrição judicial tem prevalecido no âmbito do direito processual público. Nesse campo, curiosa e paradoxalmente, a deferência dos juízes ao legislador e ao administrador encontra respaldo, agora, no novo CPC, que consagra vantagens ao Poder Público em juízo que militam contra as expectativas por um processo mais célere, justo e efetivo. Em que pese seja o único diploma processual elaborado num Estado Democrático de Direito, entulhos autoritários permanecem escamoteados nele. A comissão de renomados juristas responsáveis pela elaboração do novo Codex absteve-se de enfrentar as críticas quanto ao nosso contencioso judicial administrativo. Continuaremos, pois, tendo um processo demasiadamente moroso, injusto e irresoluto no âmbito do ramo processual em foco.

PALAVRAS-CHAVE: Celeridade; Contencioso judicial administrativo; Efetividade; Novo CPC.

\section{INTRODUÇÃO}

Nem sempre o Estado teve responsabilidade por seus atos. À época em que reinou o absolutismo, seu poder agiu completamente imune. Inexistia ilegalidade, arbitrariedade ou abusividade dos atos do Poder Público, tidos como indiscutíveis, presumidamente verdadeiros e legítimos, sempre supremos.

O poder ilimitado do Estado calhou opressão e injustiça social. Ao retirar a liberdade e até a vida das pessoas, passou a ser questionado, combatido e restringido. Após revoluções sociais e criação de cartas políticas estabelecendo direitos fundamentais de liberdade e dignidade do ser humano, oponíveis contra o Estado, os atos deste tornaram-se passíveis de controle e reprovação pelo Poder Judiciário.

'FARO - Faculdade de Rondônia - brunopastore@gmail.com 
Olhando para o Brasil, nas últimas duas décadas, o Judiciário ascendeu sobremodo como ator político, ganhando força institucional, independência e autonomia, como nunca antes. Todavia, seu ativismo e protagonismo parece tímido quando a condenação recair sobre o Estado.

Do absolutismo e autoritarismo surgiu a supremacia do interesse público sobre o particular como um princípio. Trata-se, até hoje, de um dos pilares do Direito Administrativo brasileiro, ao lado do princípio da indisponibilidade do patrimônio público e da presunção de legitimidade e legalidade dos atos administrativos. Aplicados ao processo judicial, esses princípios consagram vantagens em prol do Estado que dificultam sobremodo o acesso à Justiça pelos cidadãos, mitigando os direitos e garantias fundamentais destes, tanto materiais como processuais; até a mediação soa ineficaz.

Um processo justo, célere e efetivo são qualidades essenciais e necessárias para um Estado Democrático de Direito. A exposição de motivos do novo $\mathrm{CPC}$ reconhece como notórios os problemas da morosidade e não-efetividade da tutela jurisdicional; afirma o descrédito popular no Judiciário em decorrência disso e promete, justamente, aquelas qualidades processuais essenciais citadas, como justificativa para a revogação do CPC de 1973.

A estruturação do direito processual público é tema de especial relevo. Afinal, o novo Codex é o primeiro diploma processual pós-Constituição de 1988, o único sob a égide de um Estado Democrático de Direito. Trata-se do instrumento jurídico-processual mais utilizado para a judicialização das questões sociais, inclusive aquelas que envolvem a participação do Estado. E este, em números, é simplesmente o maior litigante, sobretudo no polo passivo.

As peculiaridades no tratamento processual da Fazenda Pública em juízo são chamadas de privilégios por alguns autores e, por outros, de prerrogativas ou pressupostos (corrente majoritária). O novo CPC os manteve, os mesmos vindos dos CPCs revogados. São institutos de blindagem da pessoa jurídica de direito público no processo, que nasceram em épocas ditatoriais, representam entulhos autoritários.

Em termos processuais, pois, parece que resquícios de absolutismo e excesso de poder estatal ainda se fazem presentes no sistema jurídico brasileiro, prejudicando milhares de cidadãos quando, tendo seus direitos subjetivos violados pelo Estado, precisam contra ele acessar a Justiça.

\section{I - CONCEITO DE DIREITO PROCESSUAL PÚBLICO E DE FAZENDA PÚBLICA E QUESTÕES TERMINOLÓGICAS}

A expressão Direito Processual Público (ou Contencioso Judicial Administrativo) serve para caracterizar o ramo do direito processual em que a pes- 
soa jurídica de direito público figura como parte, seja no polo ativo ou passivo da demanda.

A sistematização e o incremento das normas relativas à Fazenda Pública em juízo vêm ressaltando a atenção de alguns estudiosos que consideram, inclusive, já haver um regime próprio relativo ao tema, denominando-o Direito Processual Público. (CUNHA, 2016, p. 02)

Ao introduzir esse termo, BUENO pretendeu evidenciar "que determinadas regras do processo dizem respeito de forma mais aguda - senão exclusivamente - às ações em que uma das partes é o Poder Público" (2000, p. 39).

Por Poder Público, o autor refere-se às pessoas administrativas regidas, pelo menos de forma preponderante, pelo direito público. O termo também pode ser lido no art. $1^{\circ}$ da Lei $n^{\circ} 8.437 / 92$, que dispõe sobre a concessão de medidas cautelares contra atos do "Poder Público" e dá outras providências. Essa lei também utiliza os termos "órgão ou entidade" (art. $\left.1^{\circ}, \S 4^{\circ}\right)$.

Entidade deve ser interpretado como sinônimo de pessoa jurídica e não se confunde com órgão. A Lei ${ }^{\circ} 9.784 / 99$, que regula o processo administrativo no âmbito federal, define como órgão "a unidade de atuação integrante da estrutura da Administração direta e da estrutura da Administração indireta"; e define como entidade "a unidade de atuação dotada de personalidade jurídica" (art. 1", $\S 2^{\circ}$, incs. I e II, respectivamente).

É importante não confundir os termos ou utilizá-los sem critérios. Miranda Netto (2008, p. 16) ressalta dois problemas terminológicos a serem esmiuçados quando se tratar de causas em que o Estado figure como parte: o primeiro diz respeito à capacidade processual referente à parte, enquanto o segundo atrela-se ao nome do fenômeno a ser investigado.

Tecnicamente, deve-se evitar a expressão Administração Pública em juízo, visto que não se trata de pessoa jurídica do Poder Público apta a figurar como parte no processo; o termo abrange muitos órgãos e pessoas de direito público, sendo que os órgãos sequer têm a capacidade de ser parte no processo, são desmembramentos burocráticos da Administração (MELLO, 2002, p. 122)2, sem personalidade judiciária.

A expressão Fazenda Pública, por sua vez, é empregada pelo novo $\mathrm{CPC}$, em vários dispositivos, assim como era no Código revogado, constando também em outras leis. Pode representar na praxe forense a Fazenda Federal, a

\footnotetext{
${ }^{2}$ Órgãos são unidades abstratas que sintetizam os vários círculos de atribuições do Estado. Por se tratar, tal como o próprio Estado, de entidades reais, porém abstratas (seres de razão), não têm vontade nem ação, no sentido de vida psíquica ou anímica próprias que, estas, só os seres biológicos podem possuí-las. (...) Os órgãos não passam de simples partições internas da pessoa cuja intimidade estrutural integram, isto é, não têm personalidade jurídica" (p. 122)
} 
Fazenda Estadual e a Fazenda Municipal, devido ao erário da respectiva pessoa jurídica de direito público ter que responder pelas despesas da demanda.

A Administração Pública, quando ingressa em juízo por qualquer de suas entidades estatais, por suas autarquias, por suas fundações públicas ou por seus órgãos que tenham capacidade processual, recebe a designação tradicional de Fazenda Pública, porque seu erário é que suporta os encargos patrimoniais da demanda. (MEIRELLES, 1998, p. 18)

Cunha (2016, p. 5) afirma que "Fazenda Pública é expressão que se relaciona com as finanças estatais, estando imbricada com o termo Erário, representando o aspecto financeiro do ente público".

Pode-se definir a Fazenda Pública como sendo a União, os Estados, o Distrito Federal, os Municípios e, ainda, as Autarquias, as Fundações e a EBCT - Empresa Brasileira de Correios e Telégrafos (STJ, AgRg em Ag no 418.318/ DF), bem como os Conselhos responsáveis pela fiscalização das profissões (STJ, AgRg em Ag n ${ }^{\circ}$ 1388776/RJ), por serem consideradas como autarquias.

Em suma, no âmbito do direito processual público ou contencioso judicial administrativo, Estado, ente público ou pessoa jurídica de direito público são termos sinônimos de Fazenda Pública ou de Poder Público e não se confundem com órgãos ou com Administração Pública.

\section{II - DA CONFUSA DISPOSIÇÃO LEGISLATIVA DO DIREITO PROCES- SUAL PÚBLICO}

O Brasil não possui uma lei ou codificação própria para regulamentar os conflitos em que o Estado figura em juízo como parte. Essa regulação subsiste esparsamente na legislação, aqui e ali estabelecendo peculiaridades.

O novo CPC é uma dessas leis. Contém de forma espalhada ${ }^{3}$ parte dos dispositivos que formam o ramo processual em foco. É fácil exemplificar citando o art. 1.059: "À tutela provisória requerida contra a Fazenda Pública aplica-se o disposto nos arts. $1^{\circ} \mathrm{a} 4^{\circ}$ da Lei $n^{\circ} 8.437$, de 30 de junho de 1992 , e no art. $7^{\circ}, \S 2^{\circ}$, da Lei $n^{\circ} 12.016$, de 7 de agosto de 2009".

O texto não esclarece quais são as restrições, remetendo o jurista a consultar outras leis e alguns de seus dispositivos. E nada impede que esses dispositivos - já destinatários de um dispositivo legal - remetam o operador do direito a outros textos normativos.

Dallari (1997), repudiou essa técnica legislativa que "não diz direta-

${ }^{3}$ O Título VI (Da Advocacia Pública) do Livro II (Da Função Jurisdicional) do CPC, todavia, dedica-se exclusivamente ao direito processual público, em três artigos: 182, 183 e 184.

Rev. Ciênc. Juríd. Soc. UNIPAR, v. 19, n. 1, p. 25-37, jan./jun. 2016 
mente qual o conteúdo de seus dispositivos, limitando-se a fazer referência a leis, artigos e parágrafos que estão sendo alterados". Asseverou que essa prática legislativa "só se explica por má-fé ou incompetência, pois seria necessário consultar grande número de leis, entre as quais algumas do período ditatorial, para saber que direitos estavam sendo atingidos"4. Sua crítica, feita há quase vinte anos, soa mais atual hoje que outrora.

Esse modo nada didático de dispor as normas gera dificuldades de ordem hermenêutica. A reunião dos vários dispositivos legais que regulamentam a participação da Fazenda Pública em juízo forma um conjunto normativo cuja aplicação, num sistema híbrido como o nosso - que mistura o paradigma francês com o norte-americano (SILVA NETO, 2010) $)^{5}$ envolve ponderar princípios e regras não convergentes, deixando ao juiz margem para interpretações próprias ou adequadas à sua ideologia, geralmente tendente a pender para o Estado, que lhe remunera generosamente e garante benesses imorais, tal como o auxílio moradia.

A complexidade em torno da interpretação e aplicação do direito processual público, que conta com a colaboração do Poder Legislativo e Executivo, pode ser bem exemplificada pela análise da Medida Provisória ${ }^{\circ}$ 2.180-35, que em menos de 02 anos sofreu mais de 35 (re)edições. Sua origem é datada de 13.01.1999, sob o n ${ }^{\circ} 1.798$. BUENO, ao traçar o histórico dessa Medida Provisória (2008, p. 1-14), argumenta que foi prática corriqueira do Executivo Federal essas reedições bagunçadas e inconstitucionais, e provavelmente que

uma das finalidades da verdadeira confusão de edições, reedições, alteração de números, desobediência de prazos de vigência e tudo o mais - da qual a série da Medida Provisória n. 2.180 é apenas um exemplo - foi "evitar" ou "protelar" o acatamento (que se supõe, evidentemente, imediato) de decisões proferidas pela mais alta Corte brasileira. Por "coincidência", de decisões que declaravam inconstitucionais determinadas criações legislativas que só beneficiam o Poder Público em juízo, jamais o particular.

Assim, o direito processual público é disposto em atos normativos que

\footnotetext{
${ }^{4}$ Artigo intitulado "Ditadura constitucional", autoria de DALLARI, publicado na Folha de São Paulo aos 16.01.1998. Disponível em: <http://www1.folha.uol.com.br/fsp/opiniao/fz160109.htm>. Acesso em: 06.05.2016.

${ }^{5}$ SILVA NETO explica que (2010, p. 178): "O controle da Administração Pública pertence às garantias fundamentais do cidadão e deflui do princípio da separação de poderes, espécies que lhe conferem indubitável assento constitucional. Contudo, a sua concretização adentra na seara do direito administrativo, em cujo seio se desenvolve o instituto. No caso brasileiro, a Constituição sinalizou para o marco teórico norte-americano, mas a legislação ordinária, no decorrer do século passado, esmaeceu este paradigma sob matizes franceses".
} 
vão desde o novo CPC até velhos atos do período ditatorial.

\section{III - O DIREITO PROCESSUAL PÚBLICO FRENTE ÀS PROMESSAS DO NOVO CPC}

É na condição de demando que o Estado mais frequenta os fóruns e tribunais deste país ${ }^{6}$. Impressiona sua capacidade de lesar direitos fundamentais dos cidadãos. O que mais intriga, porém, é sua inércia diante do próprio ilícito contra os cidadãos, compelindo-os a acessar a Justiça. E para agravar a triste situação destes, encontrarão no processo novas ofensas ao ver o Estado bem blindado e armado.

A inércia da Administração Pública em reparar espontaneamente os danos que causa aos administrados é um dos grandes motivos da crise de efetividade e credibilidade pela qual vem passando o Judiciário, pois este não consegue cumprir sua missão em tempo razoável, de forma efetiva e justa; aceita um tratamento processual privilegiado em prol da Fazenda Pública, como se ela fosse a parte mais fraca da relação jurídica processual.

É preciso refletir melhor até que ponto defender o erário constitui-se justificativa plausível para albergar-se no ordenamento jurídico brasileiro tantos benefícios processuais fazendários. Tratando-se do instituto da remessa necessária (art. 496, CPC), por exemplo, soa ridículo aceitar a produção de uma sentença para não surtir efeitos concretos, sobretudo após ter a Fazenda Pública gozado, antes do julgado: de prazos dilatados, de restrições a provimentos provisórios contra, de intimação pessoal dos atos processuais na pessoa de seus procuradores e, até mesmo, de regras diferenciadas quanto ao ônus probatório. Depois contará com vantagens no cumprimento da sentença. Ao final, a odiosa fila de precatórios.

Tudo isso e mais tornam o cidadão extremamente fragilizado no embate processual em face do Poder Público, o qual é contumaz violador de direitos fundamentais e usa do discurso de defensor desses direitos para, de forma perversa, justificar seus privilégios processuais. Ora, é preciso termos em mente que o Judiciário não tem a missão de tutelar os interesses da Fazenda, mas sim os interesses daquele que tiver razão no litígio, sem apriorística supremacia de um em relação ao outro.

Delton Meirelles (2005, p. 272) aponta a impotência do cidadão nas causas fazendárias como reflexo de séculos de protecionismo e patrimonialismo nas relações travadas entre Estado e particular. Já Pontes de Miranda (2001, p.

\footnotetext{
${ }^{6}$ A Procuradoria Geral da Fazenda Nacional reconhece que "mais de $60 \%$ das demandas judiciais em curso são contra a Fazenda Pública" (PARECER PGFN/CRJ/No 756/2010, p. 7). Disponível em: www.pgfn.gov.br/noticias/Parecer\%20756-2010.pdf. Acesso em: 13.04.2016.
}

Rev. Ciênc. Juríd. Soc. UNIPAR, v. 19, n. 1, p. 25-37, jan./jun. 2016 
147) entende que, em virtude do vulto dos negócios do Estado, a obtenção de provas e informações pelos representantes estatais leva mais tempo que as informações e provas obtidas pelos particulares. Dinamarco (2003, p. 211), por sua vez, denuncia o tratamento anti-isonômico, asseverando que grandes empresas enfrentam problemas semelhantes e não têm o mesmo benefício. Para Nery Junior (1999, p. 48), entretanto, o indivíduo que litiga contra a Fazenda Pública não enfrenta um simples particular, mas o próprio povo, o que constitui razão suficiente para beneficiá-la quanto aos prazos.

Não se pode esquecer, é claro, que celeridade processual, embora necessidade urgente, não é valor que deva ser perseguido a qualquer custo. É lição de Barbosa Moreira (2001, p. 232):

Para muita gente, na matéria, a rapidez constitui o valor por excelência, quiçá o único. Seria fácil invocar aqui um rol de citações de autores famosos, apostados em estigmatizar a morosidade processual. Não deixam de ter razão, sem que isso implique - nem mesmo, quero crer, no pensamento desses próprios autores - hierarquização rígida que não reconheça como imprescindível, aqui e ali, ceder o passo a outros valores. Se uma justiça lenta demais é decerto uma justiça má, daí não se segue que uma justiça muito rápida seja necessariamente uma justiça boa. O que devemos querer é que a prestação jurisdicional venha ser melhor do que é. Se para torná-la melhor é preciso acelerá-la, muito bem: não, contudo, a qualquer preço.

Não obstante, é preciso mudar o cenário desagradável que é ter no Brasil um direito processual público em descompasso com a isonomia e, até, com a moralidade ${ }^{7}$ pública, na medida em que o sistema de precatórios, por exemplo, mais parece, ao menos na prática, um instrumento de calote, não obstante estar constitucionalmente estabelecido. Ruy Barbosa (2003, p. 145), em sua célere Oração aos Moços, assevera:

No Brasil, durante o Império, os liberais tinham por artigo do seu programa cercear os privilégios, já espantosos, da Fazenda Nacional. Pasmoso é que eles, sob a República, se cem-dobrem ainda, conculcando-se, até, a Constituição, em pontos de alto melindre, para assegurar ao Fisco esta situação monstruosa, e que ainda haja quem, sobre todas essas conquistas, the queira granjear a de um lugar de predileções e vantagens na consciência judiciária, no foro íntimo de cada magistrado.

\footnotetext{
${ }^{7 " N a ̃ o ~ e ́ ~ l e g i ́ t i m o ~ s u p o r ~ q u e ~ o ~ E s t a d o, ~ c r i a d o ~ p a r a ~ a t e n d e r ~ a o s ~ a n s e i o s ~ d a ~ c o l e t i v i d a d e, ~ p o s s a ~ a g i r ~ a o ~}$ largo da ética, desenvolvendo padrões de conduta controláveis apenas em termos formais. O paradigma de atuação do Estado não se esgota na legalidade estrita, adentrando na esfera moral, como demonstra o art. 37, caput, da Constituição da República" (SILVA NETO, 2010, p. 287).
}

Rev. Ciênc. Juríd. Soc. UNIPAR, v. 19, n. 1, p. 25-37, jan./jun. 2016 
O CPC de 1973 provém do anteprojeto apresentado por Alfredo Buzaid em 1964. O texto não previa a dilação de prazos nem o reexame necessário das sentenças proferidas contra a Fazenda Pública. No entanto, tais mecanismos ressurgiram no projeto encaminhado à Presidência da República e, em seguida, ao Congresso Nacional. Na Câmara dos Deputados a dilação de prazo foi impugnada pelos deputados Laerte Vieira e Peixoto Filho:

Nem mesmo a título de defesa dos interesses maiores das pessoas jurídicas de direito público, patrimoniais ou não, deve ser admitida a exceção, visto como aquelas dispõe de todo um aparato legal destinado a preservar seus interesses [...], além de contarem com pessoal altamente qualificado e geralmente bem remunerado nos seus departamentos jurídicos, para defender-lhes os direitos. [...] Por último, deve ser dito que o Estado, bem como os que o representam (caso do Ministério Público, por exemplo), têm a obrigação precípua de promover o andamento célere dos processos judiciais, eis que eles são os primeiros a proclamar tal necessidade e consagrá-la nas leis.

O novo CPC, entretanto, é pró Fazenda Pública. Em relação aos prazos dobrados, por exemplo, estenderam-se agora para toda manifestação nos autos, não mais só para interpor recursos - como dispunha o $\mathrm{CPC}$ revogado. Talvez a comissão de juristas tenha cedido a pressões externas de cunho político da classe dos detentores do poder estatal que querem manter seus benefícios em nome do "interesse público", ao argumento da "supremacia" desse interesse sobre o do particular.

O fato é que os responsáveis pela elaboração do novo CPC não enfrentaram suficientemente as críticas feitas ao nosso direito processual público, que acusam violação ao Estado de Direito, aos princípios da isonomia, da razoável duração dos processos e da efetividade.

Considerando que a Justiça se realiza pelo processo - mecanismo legitimador do poder jurisdicional - sua reformulação através do novo CPC objetivou melhor atender a demanda social brasileira, não só na busca de agilidade na resolução dos conflitos, mas também de legitimação da decisão para o jurisdicionado $^{8}$, conferindo-lhe maior participação na relação jurídica. É nesse escopo que ganhou destaque o instituto da mediação; alguns casos, tem maior potencial de pacificação ${ }^{9}$ social dos conflitos - não é o caso, porém, do contencioso judicial

${ }^{8}$ Será legítima na medida em que permitir a participação das partes através do procedimento em contraditório, associado à observância da legalidade inerente à garantia do devido processo legal. Assim, o processo só será justo quando o juiz, atento à disciplina legal, possibilitar a participação adequada e equilibrada dos indivíduos (PINHO, 2012).

9"A pacificação é o escopo magno da jurisdição e, por consequência, de todo o sistema processual (uma vez que todo ele pode ser definido como a disciplina jurídica da jurisdição e seu exercício)"

Rev. Ciênc. Juríd. Soc. UNIPAR, v. 19, n. 1, p. 25-37, jan./jun. 2016 
administrativo, cujos princípios do Direito Administrativo restringem ou mesmo inviabilizam a mediação.

A crise do Judiciário pode ser compreendida nas palavras de Luiz Fux, Ministro do STF que integrou a comissão de juristas destinada à elaboração do novo CPC:

É que; aqui e alhures não se calam as vozes contra a morosidade da justiça. O vaticínio tornou-se imediato: "justiça retardada é justiça denegada" e com esse estigma arrastou-se o Poder Judiciário, conduzindo o seu desprestígio a índices alarmantes de insatisfação aos olhos do povo.

É nesse contexto que laborou a comissão do anteprojeto. O último parágrafo da respectiva exposição de motivos sintetiza:

Em suma, para a elaboração no Novo CPC, identificaram-se os avanços incorporados ao sistema processual preexistente, que deveriam ser conservados. Estes foram organizados e se deram alguns passos à frente, para deixar expressa a adequação das novas regras à Constituição Federal da República, como um sistema mais coeso, mais ágil e capaz de gerar um processo civil mais célere e justo.

Quanto ao direito processual público, porém, em nenhum sentido foi lembrado na exposição de motivos, embora represente colossal porção das lides travadas na Justiça brasileira, conforme revelam os números do $\mathrm{CNJ}^{10}$. Vislumbra-se, portanto, grave omissão ou, talvez, propositada abstenção da comissão de enfrentar a temática.

Deve-se entender que a ordem constitucional consagra os direitos fundamentais e humanos antes dos direitos fazendários ou do Estado. Estes se apoiam na doutrina administrativa da supremacia do interesse público sobre o particular - um princípio que na prática tem abrigado inúmeros casos que representam mais os interesses da classe dominante do que os interesses efetivamente públicos.

Ora, é interesse público que a Justiça (vista como responsável por dar

(GRINOVER, 2009, p. 384).

${ }^{10} \mathrm{O}$ CNJ produziu pesquisa que aponta os 100 maiores litigantes no Brasil, revelando que na Justiça Federal, por exemplo, a grande maioria dos processos advém do setor público Federal, com $77 \%$ do total de processos dos 100 maiores litigantes dessa Justiça, enquanto os bancos são responsáveis por 19\%. "Do total de processos dos 100 maiores litigantes da Justiça Federal, 68\% referem-se ao polo passivo, sendo esse polo responsável por $69 \%$ dos processos do Setor Público Federal e por $73 \%$ dos processos do setor bancário." Disponível em: $<$ http://www.cnj.jus.br/images/pesquisas-judiciarias/ pesquisa_100_maiores_litigantes.pdf $>$ Acesso em: 12.04.2016.

Rev. Ciênc. Juríd. Soc. UNIPAR, v. 19, n. 1, p. 25-37, jan./jun. 2016 
a quem tem razão tudo aquilo que faz jus de forma célere e eficiente) seja justa. O processo requer uma apuração para saber quem, efetivamente, tem razão. Assim, enquanto pende esse estado de incerteza, as partes devem ser tratadas igualmente.

Miranda Netto, ao analisar os privilégios processuais de que goza o Estado em juízo, afirma que representam um verdadeiro regime processual de estado de exceção (2008, p. 47-65). Ou seja, na prática, estamos com nossos direitos fundamentais suspensos. Muitos discordam disso, sobretudo os autores que estão ligados a entidades públicas e ideologicamente a elas comprometidos, "conduzindo de forma tendenciosa à elaboração de teorias para a legitimação da própria prática" (p. 2).

Vale lembrar que nem sempre o Estado esteve sujeito à autoridade judiciária; o monopólio da atividade jurisdicional não o submeteu, outrora, ao seu próprio mecanismo de realização da Justiça. O Estado era imune ao poder jurisdicional, simplesmente irresponsável.

No regime absolutista não se pode falar em prerrogativas pontuais ou isoladas do Estado, pois, no sentido vetorialmente inverso, é a possibilidade de demandá-lo em juízo que ostenta caráter excepcional. A imunidade é regra; a judicialização, a exceção. (SILVA NETO, 2010, p. 173)

Atualmente, vislumbra-se que a responsabilidade estatal existe, mas de forma blindada. Não deveria ser assim. Na conjuntura atual, "as normas reguladoras do processo decorrem de um parâmetro único: o parâmetro do Estado Democrático de Direito" (DONIZETTI, 2012, p. 73).

Ora, quando o Estado se submete integralmente ao seu próprio direito, mas reserva para si faculdades não concedidas aos cidadãos, produz-se o debate acerca da legitimidade desse regime específico ${ }^{11}$. Há ofensa à isonomia, pois o Estado não é a parte mais fraca na relação jurídica processual.

\section{CONSIDERAÇÕES FINAIS}

A história da humanidade demonstra que a limitação do poder é conquista relativamente recente, para não se dizer ainda em curso, em permanente conflito dialético. Nessa esteira, é possível perceber expressões questionáveis desse poder presentes ainda hoje no direito processual público brasileiro, de forma não tão autoritária, mas longe do ideal; um autoritarismo disfarçado de justiça

\footnotetext{
11'"Esses privilégios decorrem da concepção francesa do direito administrativo, ligado à ideia do regime administrativo; eles contrastam com a concepção anglo-saxônica, segundo a qual o Estado se submete ao juiz nas mesmas conduções que os cidadãos" (GRECO FILHO, 1989, p. 95).
}

Rev. Ciênc. Juríd. Soc. UNIPAR, v. 19, n. 1, p. 25-37, jan./jun. 2016 
social, como se o erário realmente fosse revertido ao povo. Pagamos os mais altos impostos do mundo e temos um Estado incapaz de retornar esses recursos em serviços essenciais básicos.

Mas, se o novo CPC tivesse abandonado completamente as chamadas prerrogativas do Poder Público em juízo, devido raízes no regime ditatorial ou porque "se pretendeu alcançar na República a isonomia que não se conheceu no Império" (SILVA NETO, 2010, p. 31), imitando o regime processual norte-americano, certamente não haveria boa aceitação pelas instituições político-jurídicas estabelecidas. Afinal, elas são as beneficiárias dos privilégios/prerrogativas.

São vários os obstáculos ao acesso à Justiça ainda existentes quando nos deparamos com o direito processual público. Já passou da hora de entrevermos instrumentos aptos a minimizar essa desigualdade sociocultural entre as partes, para que o resultado do processo não seja fruto desse desequilíbrio e, assim, possa a Justiça conquistar mais credibilidade em sua atuação.

A conclusão inarredável é que são falaciosas as promessas centrais do novo CPC se tivermos em conta apenas o contencioso judicial administrativo.

\section{REFERÊNCIAS}

BANDEIRA DE MELLO, C. A. Curso de direito administrativo. 14 ed. São Paulo: Malheiros, 2002.

BARBOSA, R. Oração aos Moços. São Paulo: Ed. Papagaio, 2003.

BUENO, C. S. O Poder Público em Juízo. São Paulo: Saraiva, 2008.

CAMPOS, C. A. de A. Dimensões do ativismo judicial do supremo Tribunal Federal. Rio de Janeiro: Forense, 2014.

CUNHA, L. C. de. A Fazenda Pública em Juízo. Rio de Janeiro: Forense, 2016.

DIDIER JR., F. Curso de direito processual civil: introdução ao direito processual civil, parte geral e processo de conhecimento. 17. ed. Salvador: Jus Podivm, 2015.

DINAMARCO, C. R. Instituições de Direito Processual Civil. 3. ed. São Paulo: Malheiros, 2003, vol. III.

FAGUNDES, M. S. O controle dos atos administrativos pelo Poder

Judiciário. 7. ed., atualizada por Gustavo Binenbojm. Rio de Janeiro: Forense, 
2005.

GRECO FILHO, V. Tutela constitucional das liberdades. São Paulo, Saraiva, 1989.

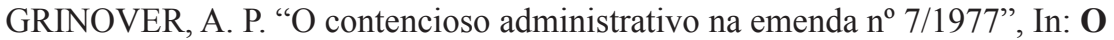
processo em sua unidade. São Paulo: Saraiva, 1978.

MEIRELLES, D. R. S. “Juízos privativos da Fazenda Pública no Império” In: VI Mostra de Pós-graduação. Taubaté: UNITAU, 2005.

MEIRELLES, H. L. Direito administrativo brasileiro. 23 ed. atual. por Eurico de Andrade Azevedo, Délcio Balestero Aleixo e José Emmanuel Burle Filho. São Paulo: Malheiros, 1998.

MIRANDA, F. C. P. de. Comentários ao Código de Processo Civil. Atualização: Sérgio Bermudes, $4^{\mathrm{a}}$ ed. $3^{\mathrm{a}}$ tir., 2001, tomo III.

MIRANDA NETTO, F. G. de. Ônus da prova no direito processual público: Contencioso judicial administrativo entre o direito ao ônus da prova justo e a presunção de legitimidade dos atos da Administração Pública. Rio de Janeiro: Lumen Juris, 2008.

NERY JUNIOR, N. Princípios do Processo Civil na Constituição Federal. 5. ed. São Paulo: RT, 1999.

OLIVEIRA, D. de. A limitação da supremacia do interesse público. Escola da Magistratura: Rio de Janeiro, 2009.

SILVA NETO, F. A. de B. A improbidade processual da administração Pública e sua responsabilidade objetiva pelo dano processual. Rio de Janeiro: Lumen Juris, 2010.

\title{
RESISTANCE OF THE PUBLIC PROCESS RIGHT ON THE PROMISE OF NEW CODE OF CIVIL PROCEDURE CODE
}

\begin{abstract}
The explanatory to the statement of the new CPC reasons, recognizing that justice delayed is a denied justice exalts the principle of the reasonable duration of proceedings and effectiveness, so that every costumer interpretation and application of the law to the particular case. Despite the rise and strengthening of the Judiciary, endowed with autonomy and independence
\end{abstract}


as never before happened in Brazil, judicial auto-restriction has prevailed in the public procedural law. In this field, curiously and paradoxically, the deference of the judges to the legislator and the administrator is supported now in the new CPC, which enshrines advantages to the Government in court that militate against expectations for quick, fair and effective process. In spite of procedural law being the only developed a democratic state, the authoritarian rubbles remain concealed it. The committee of renowned jurists responsible for drafting the new Codex refrained from facing criticism about our administrative litigation. We will continue, therefore, having a too lengthy, unfair and irresolute process under the procedural branch in focus.

KEYWORDS: Administrative litigation; Effectiveness; New CPC.

\section{RESISTENCIAS DEL DERECHO PROCESAL PÚBLICO - LAS PROMESAS DEL NUEVO CÓDIGO DE PROCESO CIVIL}

RESUMEN: La exposición de motivos del nuevo CPC, reconociendo que justicia retrasada es justicia denegada, exalta los principios de la duración razonable de los procesos y de la eficacia, para que pauten toda interpretación y aplicación del derecho al caso concreto. No obstante, la ascensión y fortalecimiento del Judiciario, dotado de autonomía e independencia como nunca antes en Brasil, la restricción judicial ha prevalecido en el ámbito del derecho público procesal. En ese campo, curiosa y paradójicamente, la deferencia de los jueces al legislador y al administrador encuentra respaldo en el nuevo CPC, que consagran ventajas al Poder Público en juicio que militan contra las expectativas por un proceso más célere, justo y efectivo. A pesar que sea el único diploma procesal elaborado en un Estado Democrático de Derecho, escombros autoritarios permanecen ocultos en él. El comité de renombrados juristas, responsables por la elaboración del nuevo Codex se abstienen de enfrentar las críticas cuanto a nuestro contencioso administrativo judicial. Continuaremos, por lo tanto, teniendo un proceso demasiado largo, injusto e irresoluto en el ámbito del área procesal en foco.

PALABRAS CLAVE: Celeridad; Contencioso administrativo judicial; Efectividad; Nuevo CPC. 